Tropical Journal of Pharmaceutical Research, December 2009; 8 (6): 545-550

(C) Pharmacotherapy Group, Faculty of Pharmacy, University of Benin,

Benin City, 300001 Nigeria.

All rights reserved.

Research Article

Available online at http://www.tjpr.org

\title{
Galangoflavonoid Isolated from Rhizome of Alpinia galanga (L) Sw (Zingiberaceae)
}

\author{
SB Jaju ${ }^{1 \star}$, NH Indurwade ${ }^{1}$, DM Sakarkar ${ }^{1}$, NK Fuloria $^{2}$, MD Ali $^{3}, \mathrm{~S}$ \\ Das $^{4}$ and SP Basu ${ }^{4}$ \\ ${ }^{1}$ S.N. Institute of Pharmacy, Pusad, Amravati University, M.S -445 204, ${ }^{2}$ Ram-eesh Institute of Vocational and \\ Technical Education, Knowledge Park-II, Greater Noida, UP 201 306, ${ }^{3}$ Department of Pharmacognosy, Jamia \\ Hamdard, New Delhi, 110 062, ${ }^{4}$ Department of Pharmaceutical Technology, NIET, Knowledge park -II, Greater \\ Noida, UP, 201 306, India
}

\begin{abstract}
Purpose: The purpose of this investigation was to isolate novel flavonoids from Alpinia galanga rhizomes.

Methods: The methanol extract of Alpinia galanga was subjected to column chromatography and eluted with ethyl acetate-methanol (9:1) to yield a compound, galangoflavonoside (AG 11). The structure of the compound was elucidated by various spectral techniques (UV, IR, ${ }^{1} \mathrm{H} N \mathrm{NM},{ }^{13} \mathrm{C} N \mathrm{NMR}$, and MS).

Results: Chemical investigation of the extract furnished a new flavonoid galangoflavonoside (AG 11). Conclusion: The isolated compound, galangoflavonoside (AG 11,) could be a potential therapeutic compound as well as serve as a lead compound in the synthesis of other useful flavonoids. Isolation of the galangoflavonoside from Alpinia galanga rhizomes is being reported, to the best of our knowledge, for the first time.
\end{abstract}

Keywords: Alpinia galangal; Methanol extract; Galangoflavonoside; Spectral techniques 


\section{INTRODUCTION}

Alpinia galanga (L.) Sw. (Zingiberaceae) is a perennial herb with rhizomatous root stocks and tall leafy stems. It is commonly known as greater galangal $[1,2]$. This plant is reported to be rich in essential oils such as cineole, methyl cinnamate, myrecene, and methyl eugneol and is also said to contain various flavones such as galangin, alpinin, kampferide and 3-dioxy-4-methoxy flavone $[3,4]$. It is known to possess antimicrobial, antioxidant, antifungal, anti-cancer, and gastroprotective activities [5-7]. The present paper reports the isolation of flavone glycoside from the plant and its structural elucidation by spectroscopic methods, including ultraviolet spectroscopy (UV), infrared spectroscopy (IR), nuclear magnetic resonance (NMR) and mass spectrometry (MS).

\section{EXPERIMENTAL}

\section{Plant material}

The dried rhizomes of Alpinia galanga (Zingiberaceae), collected in Pusad Province of India, were identified by Prof. Anjula Pandey, a taxonomist of the National Bureau of Plant Genetic Resources, Pusa, New Delhi. A voucher specimen, no. EP-542, was deposited in the herbarium of the Natural Medicines Research Center of S.N. Institute of Pharmacy, Pusad, Amravati University.

\section{Extraction and isolation}

Dried, ground rhizome of Alpinia galanga $(3000 \mathrm{~g})$ was defatted with $5.5 \mathrm{~L}$ of petroleum ether $\left(60-80{ }^{\circ} \mathrm{C}\right)$, and successively extracted with $7.5 \mathrm{~L}$ of methanol using Soxhlet apparatus. The methanol extract was evaporated on a waterbath to yield a dark brown solid (35 g), which was subjected to Si-gel column chromatography (100-120 mesh) and eluted with ethyl acetate:methanol $(9: 1)$ to give a compound weighing $47 \mathrm{mg}$. In the Shinoda test [8], $95 \%$ ethanol, $\mathrm{HCl}$ and magnesium turning were added to compound AG 11 and boiled for $1-2 \mathrm{~min}$. A positive test is indicated by magenta colour. In the lead acetate test [8], lead acetate was added to compound AG 11, and a positive is indicated by yellow colour.

\section{Acid hydrolysis of compound AG11}

Compound AG11 (20 mg) was dissolved in 5 $\mathrm{ml}$ of $2 \mathrm{M} \mathrm{HCl}$ :methanol (1:1) and refluxed for $1 \mathrm{~h}$. The solvent was evaporated completely under vacuum. The residue was dissolved in water $(5 \mathrm{ml})$ extracted with petroleum ether to separate oleic acid, and extracted with ethyl acetate $(3 \times 5 \mathrm{ml})$ to remove flavones and aglycones. The sugars present in aqueous phase were detected by TLC with the aid of standard samples of D-glucose $(R f=0.12)$ and L-arabinose $\left(R_{f}=0.18\right)$ and with $n$ butanol:acetic acid: water $(4: 1: 5)$ as the top layer.

\section{Melting point and spectroscopic analysis of Isolate}

Melting point was determined in an open capillary with Perfit melting point apparatus and was uncorrected. IR spectrum was recorded on Jasco FTIR-550 spectrophotometer using a thin film supported on KBR pellets, and values were reported as $\mathrm{v}_{\max }\left(\mathrm{cm}^{-1}\right)$. ' $\mathrm{H}$ NMR and ${ }^{13} \mathrm{C}$ NMR spectra were recorded on a Bruker DPX 300 (Bruker) system using DMSO as solvent. The chemical shift values were reported as values in ppm relative to tetramethyl silane (TMS, $\delta$ $=0$ ) as internal standard. The mass spectrum was generated on FAB-JEOL-MS 303 system (JEOL) mass spectrometer operating at 70 $\mathrm{eV}$, by fast atomic bombardment technique, using xenon as the carrier gas. The purity of the isolated compound AG 11 was determined (by observation of a single spot in a UV and iodine chamber) on aluminium TLC sheets coated with Silica gel 60 F254 (0.2 $\mathrm{mm}$ thick, Hi Media), using EtOAc-MeOH $(9.5: 0.5)$ solvent system. 


\section{RESULTS}

Following column chromatography over silica gel using ethyl acetate:ethanol (9:1), a pale yellow crystalline mass of compound (AG 11) was obtained. The compound (AG 11) was positive to Shinoda and lead acetate tests for flavonoid glycosides. The compound (AG 11) was pure as indicated by a single spot with an $R_{f}$ value of 0.63 in EtOAc-MeOH (9.5:0.5) solvent system. Its melting point was 188$190^{\circ} \mathrm{C}$ (uncorrected). IR bands occurred at $3510,3418,3375,2926,1733,1690,1652$, 1516, 1456, 1228, $1076 \mathrm{~cm}^{-1}$. Positive FABMS m/z was 530 (10.5), 433 (20.3), 398 (65.7), 330 (17.8), 281 (7.5), 265 (61.2), 179 (21.5), 163 (32.8), 150 (33.1), 149 (67.2), 134 (39.1), 133 (86.9). ${ }^{1} \mathrm{H}-\mathrm{NMR}$ and ${ }^{13} \mathrm{C}-\mathrm{NMR}$ data are listed in Table 1.

\section{DISCUSSION}

On the basis of the mass spectral fragmentation pattern, its molecular formula was established as $\mathrm{C}_{77} \mathrm{H}_{114} \mathrm{O}_{44}$. The characteristic UV spectrum of the molecule: UV $\lambda_{\max } \mathrm{MeOH}: 276,315 \mathrm{~nm}\left(\log _{\varepsilon} 5.3,1.6\right)$, $\lambda \max \mathrm{MeOH}+\mathrm{NaOAc}: 276,314 \mathrm{~nm}, \lambda \max$ $\mathrm{MeOH} \mathrm{I}+\mathrm{NaOAC}+\mathrm{H} 3 \mathrm{BO} 3: 275,310 \mathrm{~nm}, \lambda$ $\max \mathrm{MeOH}+\mathrm{MeONa}: 281,325 \mathrm{~nm}$, and $\lambda$ meOH $+\mathrm{AlCl}_{3}+\mathrm{HCl}: 279,370 \mathrm{~nm}$ is indicative of a flavone nature. Its IR spectrum showed characteristic absorption bands for hydroxyl groups $\left(3510,3418,3375 \mathrm{~cm}^{-1}\right)$ and ester group $\left(1733 \mathrm{~cm}^{-1}\right)$.

The ${ }^{1}$ HNMR spectrum of the compound showed signals at $\delta 6.67(\mathrm{br}, \mathrm{H}-8), \delta 7.23(\mathrm{~m}$, $\left.\mathrm{H}-2^{\prime}\right)$ and $\delta 7.31\left(\mathrm{~m}, \mathrm{H}-6^{\prime}\right)$ as well as two (one proton) doublets for C-2" methylene protons adjacent to the ester linkage at $\delta 2.60$ $(\mathrm{J}=11.3 \mathrm{~Hz})$ and $\delta 2.57(\mathrm{~J}=11.3 \mathrm{~Hz})$. A threeproton triplet at $\delta 0.88(\mathrm{~J}=11.3 \mathrm{~Hz})$ was ascribed to C-18" terminal primary methyl protons. Signals that appeared at $\delta 5.36(2 \mathrm{H}$, $\mathrm{m})$ and $\delta 5.33(2 \mathrm{H}, \mathrm{m})$ were ascribed to $\delta \mathrm{C}$ $9 "$ and $\delta$ C-10" vinylic protons, respectively. The remaining methylene protons appeared between $\delta 1.52-1.08$. The anomeric protons

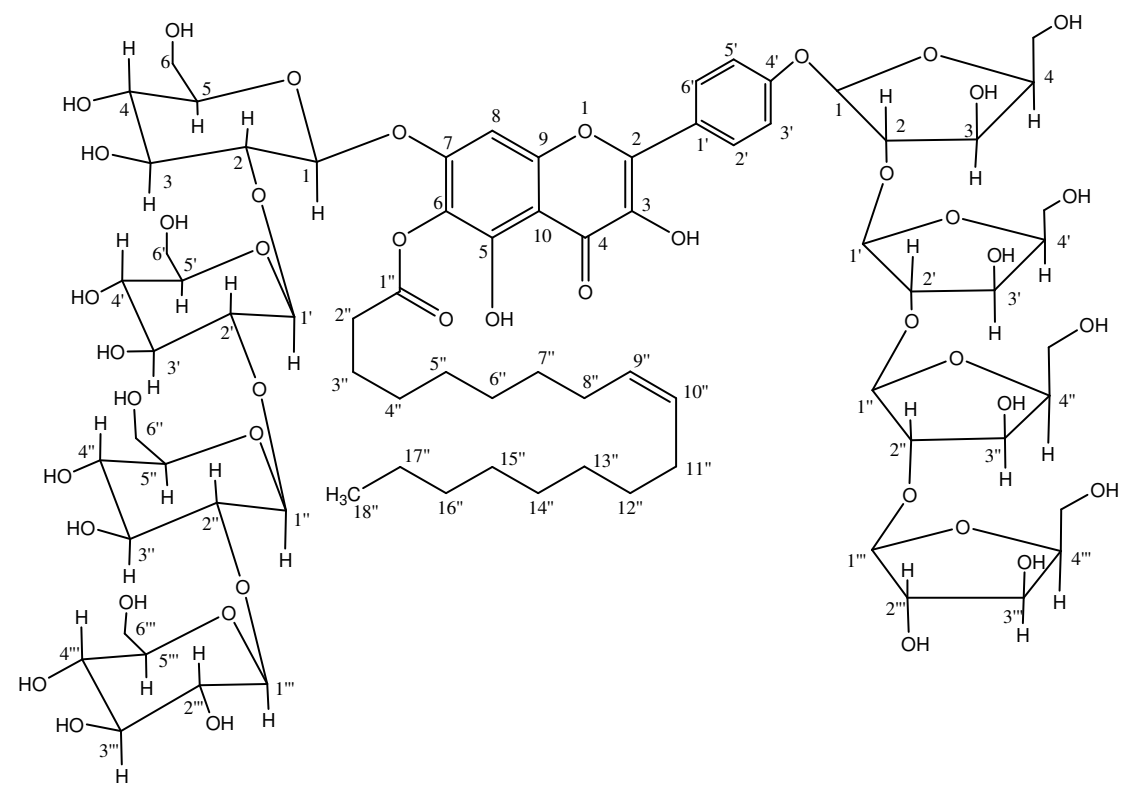

Fig 1: Compound AG 11: IUPAC NAME: 3, 5, 6, 7, 4'-Pentahydroxyflavone-6-(9"-octadeconoate)-7-[ $\beta$-Dglucopyranosyl(G-2 $\rightarrow$ G-1')- $\beta$-D-glucopyranosyl(G-2' $\rightarrow$ G-1")- $\beta$-D-glucopyranosyl(G-2" $\rightarrow$ G-1'”)]-4'-[ $\beta$-Larabinofuranosyl-(A-2 $\left.\rightarrow A-1^{\prime}\right)-\beta$ - $L$-arabinofuranosyl-(A-2' $\rightarrow A-1$ "')- $\beta$-L-arabinofuranosyl-(A-2" $\rightarrow A-1$ "' $)-\beta-L$ arabinofuranoside. 
Jaju et al

Table 1: ${ }^{1} \mathrm{H}$ and ${ }^{13} \mathrm{C}$ NMR data for compound AG 11 (a galangoflavonoside)

\begin{tabular}{|c|c|c|}
\hline Position & 1NNMR & ${ }^{13}$ CNMR \\
\hline 1 & ……….. & $\ldots$. \\
\hline 2 & ............. & 146.12 \\
\hline 3 & ……… & 136.49 \\
\hline 4 & ............ & 173.81 \\
\hline 5 & ............. & 152.11 \\
\hline 6 & (............. & 129.93 \\
\hline 7 & & 166.52 \\
\hline 8 & $6.67 \mathrm{~s}$ & 92.68 \\
\hline 9 & …........ & 152.17 \\
\hline 10 & ........... & 103.58 \\
\hline 1 & $\ldots \ldots \ldots \ldots$ & 121.29 \\
\hline 2 & $7.23 \mathrm{~m}$ & 115.39 \\
\hline 3 & $6.71 \mathrm{~m}$ & 134.35 \\
\hline 4 & & 147.48 \\
\hline 5 & $6.71 \mathrm{~m}$ & 115.93 \\
\hline 6 & $7.31 \mathrm{~m}$ & 122.85 \\
\hline $1 "$ & & 171.01 \\
\hline 2" & $2.60 \mathrm{~d}(11.3), 2.58 \mathrm{dd}(11.3)$ & 56.04 \\
\hline $3 "$ & $1.52 \mathrm{~m}$ & 48.14 \\
\hline 4" & $1.52 \mathrm{~m}$ & 33.48 \\
\hline $5 "$ & $1.27 \mathrm{brs}$ & 31.47 \\
\hline 6" & $1.27 \mathrm{brs}$ & 31.11 \\
\hline 7" & $1.27 \mathrm{brs}$ & 30.68 \\
\hline 8" & $2.47 \mathrm{~m}$ & 51.56 \\
\hline 9" & $5.36 \mathrm{~m}$ & 130.17 \\
\hline $10 "$ & $5.33 \mathrm{~m}$ & 129.85 \\
\hline $11 "$ & $2.03 \mathrm{~m}$ & 51.97 \\
\hline $12 "$ & $1.91 \mathrm{~m}$ & 30.02 \\
\hline $13^{\prime \prime}$ & $1.27 \mathrm{brs}$ & 29.22 \\
\hline $14 "$ & $1.27 \mathrm{brs}$ & 28.97 \\
\hline $15 "$ & $1.27 \mathrm{brs}$ & 28.82 \\
\hline $16 "$ & $1.14 \mathrm{~m}$ & 24.61 \\
\hline $17 "$ & $1.08 \mathrm{~m}$ & 22.25 \\
\hline $18 "$ & $0.88 \mathrm{t}(6.2)$ & 14.02 \\
\hline G-1 & $5.01 \mathrm{~m}$ & 102.08 \\
\hline G-2 & $3.89 \mathrm{~m}$ & 71.66 \\
\hline G-3 & $3.65 \mathrm{~m}$ & 70.26 \\
\hline G-4 & $3.47 \mathrm{~m}$ & 69.32 \\
\hline G-5 & $4.21 \mathrm{~m}$ & 76.83 \\
\hline G-6, & $3.13 d(8.5), 3.09 d(8.5)$ & 61.36 \\
\hline G-1 & $5.00 \mathrm{~m}$ & 100.73 \\
\hline G-2' & 3.09 & 71.64 \\
\hline G-3' & $3.64 \mathrm{~m}$ & 69.29 \\
\hline G-4' & $3.63 \mathrm{~m}$ & 67.19 \\
\hline G-5' & $4.20 \mathrm{~m}$ & 75.42 \\
\hline G-6' & $3.13 d(8.5), 3.09 d(8.5)$ & 61.31 \\
\hline G-1" & $4.99 \mathrm{~m}$ & 100.73 \\
\hline G-2" & $3.88 \mathrm{~m}$ & 70.71 \\
\hline G-3" & $3.63 \mathrm{~m}$ & 67.14 \\
\hline G-4" & $3.67 \mathrm{~m}$ & 65.38 \\
\hline G-5” & $4.19 \mathrm{~m}$ & 73.13 \\
\hline G-6" & $3.13 d(8.5), 3.09 d 8.5$ & 60.09 \\
\hline
\end{tabular}


Jaju et al

Table 2: ${ }^{1} \mathrm{H}$ and ${ }^{13} \mathrm{C}$ NMR data for compound AG 11 (a galangoflavonoside) ..contd

\begin{tabular}{|c|c|c|}
\hline Position & ${ }^{1}$ HNMR & ${ }^{13}$ CNMR \\
\hline G-1'”' & $4.098 \mathrm{~m}$ & 88.53 \\
\hline G-2'” & $3.87 \mathrm{~m}$ & 70.29 \\
\hline G-3"' & $3.62 \mathrm{~m}$ & 66.52 \\
\hline G-4'”' & $3.65 \mathrm{~m}$ & 66.55 \\
\hline G-5”' & $4.18 \mathrm{~m}$ & 75.86 \\
\hline G-6”' & $3.06 d(9.01), 3.03 d(9.01)$ & 60.03 \\
\hline$A-1$ & $5.01 \mathrm{~m}$ & 104.75 \\
\hline$A-2$ & $4.31 \mathrm{~m}$ & 78.78 \\
\hline$A-3$ & $3.47 \mathrm{~m}$ & 73.99 \\
\hline$A-4$ & $4.50 \mathrm{~m}$ & 82.81 \\
\hline$A-5$ & $3.23,3.20 \mathrm{brs}$ & 64.49 \\
\hline$A-1$ & $5.00 \mathrm{~m}$ & 104.71 \\
\hline A-2' & $4.30 \mathrm{~m}$ & 77.67 \\
\hline A-3' & $3.46 \mathrm{~m}$ & 73.96 \\
\hline A-4' & $4.50 \mathrm{~m}$ & 82.72 \\
\hline$A-5$ & $3.23,3.20 \mathrm{brs}$ & 64.01 \\
\hline$A-1 "$ & $5.00 \mathrm{~m}$ & 102.08 \\
\hline A-2" & $4.30 \mathrm{~m}$ & 75.86 \\
\hline A-3” & $3.31 \mathrm{~m}$ & 73.52 \\
\hline A-4" & $4.31 \mathrm{~m}$ & 81.99 \\
\hline$A-5^{\prime \prime}$ & $3.23,3.20 \mathrm{brs}$ & 63.07 \\
\hline$A-1^{\prime \prime \prime}$ & $4.98 \mathrm{~m}$ & 102.08 \\
\hline A-2"' & $4.29 \mathrm{~m}$ & 77.82 \\
\hline A-3"' & $3.31 \mathrm{~m}$ & 72.55 \\
\hline A-4"' & $4.30 \mathrm{~m}$ & 81.41 \\
\hline$A-5 "$, & $3.23,3.20 \mathrm{brs}$ & 62.20 \\
\hline
\end{tabular}

resonated as multiplets between $\delta$ 5.01-4.98. The oxygenated methylene protons were present as doublets between $\delta$ 3.13-3.03 and as broad signals between $\delta 3.23-3.20$. The other sugar protons appeared in the range of $\delta$ 4.20-3.09.

The ${ }^{13} \mathrm{C}$ NMR spectrum of the compound exhibited carbon signals for carbonyl carbon at $\delta 173.81(\mathrm{C}-4)$, ester carbons at $\delta 171.01$ (C-1"), vinylic carbons at $\delta 130.17$ (C-9") and $\delta 129.85$ (C-10"), methyl carbon at $\delta 14.02$ (C-18"), anomeric carbons between $\delta$ 104.75-88.53. The signals for flavone ring carbons appeared between $\delta$ 166.52-103.58. The signals for other sugar carbons appeared in the range of $\delta 82.81$ - 60.03. The appearance of G-2, G-2', G-2" and G-2'" in slightly deshielded region at $\delta 71.66,71.66$, $71.64,70.71$, and 70.79 , respectively and $A-2$, A-2', A-2",A-2'"' and A-2'"' at 78.78, $\delta$ 77.67, $\delta 75.86, \delta 77.82$ and $\delta 76.83$, indicated $a$ sugar linkage of one $\mathrm{C}-2$ to the anomeric proton of the other sugar moiety. Acid hydrolysis of the compound yielded oleic acid, D-glucose, L-arabinose and the flavones. On the basis of the above discussion, the structure of compound AG 11 has been elucidated as $3,5,6,7,4$ 'pentahydroxyflavone-6-(9"-octadeconoate)-7[ $\beta$-D-glucopyranosyl(G-2 $\rightarrow$ G-1')- $\beta$-Dglucopyranosyl(G-2' $\rightarrow$ G-1") $-\beta-D$ glucopyranosyl(G-2"' $\rightarrow$ G-1'”)]-4'-[ $\beta-L-$ arabinofuranosyl-(A-2 $\left.\rightarrow A-1{ }^{\prime}\right)-\beta-L-$ arabinofuranosyl-(A-2' $\rightarrow A-1$ '")- $\beta$-Larabinofuranosyl-(A-2"' $\rightarrow A-1$ '”) $-\beta-L-$ arabinofuranoside.

\section{CONCLUSION}

The present study has isolated and characterized a new flavone, galangoflavonoside, from Alpinia galanga rhizomes for the first time. Further pharmacological investigations are underway to investigate the biological activity of the isolated compound 


\section{ACKNOWLEDGMENT}

The authors are grateful to Dr NJ Duragkar, Professor, S. P College of Pharmacy, Nagpur and Dr Rashmi Shukla, Prof. Mumbai Technical Institute of Pharmacy, Mumbai valuable support and suggestions. Thanks are due also to CDRI Lucknow, Indian Institute of technology, Delhi and Arbro Pharmaceuticals, Delhi for assistance in carrying out spectral analyses.

\section{REFERENCES}

1. Kirtikar KR, Basu BD. IndianMmedicinal Plants. Deraduhun International Book Distributors, 1996. pp. 2445.

2. Asolkar LV, Kakkar KK, Chakre OJ. Second Supplement to "Glossary of Indian Medical
Plants with Active Principles". Part - I (A-K), 1992, pp 50-51.

3. The Wealth of India, National Institute of Science Communication and Information Resources Council of Scientific and Industrial Research, New Delhi, 2005.

4. Cui $Z$, Determination of chemical constituents of the essential oil from Alpinia galanga (L.) by GCMS. Lixueban, 2003; 38: 104-107.

5. Janssen AM, Scheffer JC, Acetoxychavicol acetate an antifungal component of Alpinia galanga. Planta Medica, 1985: 507-511.

6. Jirawan $O$, Tomoko $S$. Antimicrobial properties and action of galangal (Alpinia galanga Linn.) on Staphylococcus aureus. LWT-Food and Science Technology, 2006; 39: 1214-1220

7. Matsuda H, Morikawa T. Gastro protective effects of phenyl propanoids from the rhizomes of Alpinia galanga in rats: structural requirements and mode of action. European Journal of Pharmacology, 2005; 471: 59-67. 